\title{
Climate Change Impact and Mitigation In Marine Biodiversity Conservation
}

\section{S. Naveen Nivas and ${ }^{2}$ Dr. I. Sundar}

${ }^{1}$ B.F.Sc Student, Center for Advanced Studies in Marine Biology, Annamalai University ${ }^{2}$ Associate Professor of Economics, Directorate of Distance Education, Annamalai University

Correspondence Author: S. Naveen Nivas, B.F.Sc Student, Center of Advanced Studies in Marine Biology, Annamalai University.

Received date: 22 June 2018, Accepted date: 16 August 2018, Online date: 8 September 2018

Copyright: (C) 2018 S. Naveen Nivas and Dr. I. Sundar. This is an open-access article distributed under the terms of the Creative Commons Attribution License, which permits unrestricted use, distribution, and reproduction in any medium, provided the original author and source are credited.

\begin{abstract}
Marine life faces challenges from warming waters and ocean acidification. Warming waters alter the latitude and depth at which certain species are able to survive, so many species are moving deeper or father north in the Atlantic to find cold water. Overall, marine species are responding to warmer temperatures by moving northward or deeper when possible in search of cooler waters. This paper deals with impact of climate change and marine biodiversity. It outlines the climate change impact on marine microscopic organisms, marine plants, corals reefs, marine fish, marine mammals, marine reptiles and seabed dwellers. This paper makes a special note on climate change mitigation option in conservation of marine biodiversity. This paper concludes with some interesting findings along with policy measures.
\end{abstract}

Key words:

\section{INTRODUCTION}

Marine life is affected by variations in water temperature, in oxygen concentrations, in acidification, in the severity of extreme climate events and in ocean biogeochemical properties. These changes have either direct or indirect effects on the metabolism of individuals (growth, respiration, etc.), on the life cycles of species, on the relationship between prey and predators and on changes in habitat. It is evident from the work done by [1] that they affect both the individual level, and the interactions between species and habitats, thus triggering changes in species assemblages, but also in productivity and ecosystem resilience.

The disturbances are now clearly established across a wide range of taxonomic groups ranging from plankton to top predators and in agreement with the theoretical approaches regarding the impact of climate change [2] and [3], demonstrated that large-scale changes were occurring in the biogeography of calanoid crustaceans in the northeast Atlantic Ocean and European continental seas. Northward shifts of warm water species by more than $10^{\circ}$ latitude coinciding with a decrease in the number of cold-water species are related both to the rise in temperature in the Northern Hemisphere and to the North Atlantic Oscillation.

Poloczanska, shows that changes in phenology, distribution and abundance are overwhelmingly (81\%) in accordance with the expected responses in a context of climate change. A large number of biological events concerning maximal phytoplankton abundance as well as reproduction and migration of invertebrates, fish and seabirds, all take place earlier in the year. Hence, since the past fifty years, the Spring events have been shifting earlier for many species by an average of $4.4 \pm 0.7$ days per decade and the summer events by $4.4 \pm 1.1$ days per decade. Observations show that for all taxonomic groups, but with great heterogeneity, the rate of displacement towards the poles reaches $72.0 \pm 13.5$ kilometers per decade. Changes in distribution of benthic, pelagic and demersal species can extend up to a thousand kilometers. These poleward migrations have led to an increase in the number of warm-water species in areas like the Bering Sea, the Barents Sea or the North Sea. As per the report by [4] observed modifications in the distribution of benthic fish and shellfish with latitude and depth can be mainly explained by changes in the temperature of the sea. The migration rates recorded in the marine environment appear to be faster than observed in the terrestrial environment.

[5,6] have shown that changes in temperature and in ocean chemistry affect the growth, reproduction and physiology of marine organisms. [7,8], and [9] shown that fish body size may be reduced due to climate change, especially in response to warming, reduction in oxygen, and resource availability. In a metaanalysis of the effect of climate on fish body size . showed a significant increase in the proportion of small-sized species and young age classes and a decrease in size-at-age, in accordance with Bergmann's rule concerning temperature vs. size. According to the IPCC (Intergovernmental Panel on Climate Change), oceans are projected to become warmer and less oxygenated (IPCC 2014).

Climate plays a key role in the dispersal success of exotic fish species:

It is observed from the work done by Duncan et al. that the invasion success of some exotic species has been shown to be positively related to the match between native and colonized environments. In particular, a species that is introduced in similar thermal conditions is more likely to establish successfully. This is called the "climate match" hypothesis, and it appears to play a key role in the invasion rate in the Mediterranean Sea. [10] note that the greater dispersal success of Lesseps Ian species was associated with thermal conditions prior to 1980 crossing the Suez Canal does not necessarily guarantee successful invasion and widespread dispersal of fish populations.

Climate change impacts on microscopic organisms:

Rising sea temperatures, changes to ocean currents and ocean acidification are the main factors that will affect microscopic organisms. Because they are short-lived (and go through many generations in a short time), microscopic organisms will have a better chance of adapting to environmental changes than many other species groups. 
It could be noted that rising sea temperatures has effect on microscopic organisms in marine ecosystem. The researchers such as $[11,12,13]$ have indicated the various impacts of climate change on micro organism in the marine environment. The outcome of such studies are quite relevant from the point of view of following discussion.

It is observed that rising sea temperatures will affect the growth, reproduction and survival of microscopic organisms. Different species will react in different ways, and this will alter the interactions between organisms as well.

One well-known consequence of rising sea temperature is coral bleaching. Bleaching occurs when corals expel the microscopic algae that live within the coral tissue. Some of these algae can tolerate higher temperatures than others and corals have been found to swap heat-sensitive algae for more resistant strains to try to prevent bleaching. Higher sea temperatures are also expected to favour a range of microscopic organisms that cause disease. Some types of coral diseases already appear to be occurring more often as the climate changes.

The changes in ocean currents consequent up on climate change can affect the marine micro organisms. It could be noted that the rising sea temperatures are also likely to reduce the supply of essential nutrients for the tiny plants that support the open ocean food web. These microscopic plants known as phytoplankton rely on nutrients that are brought up from deeper in the ocean. As surface water warms, it becomes less dense and does not mix as readily with the cooler water below. This makes it harder for nutrients to reach the surface, reducing the production of phytoplankton. This in turn affects the food supply for the entire open ocean food chain, including fish, seabirds, whales and dolphins. Other changes to ocean currents will also affect the transport of microscopic eggs and larvae within and between coral reefs.

The impact of climate change results in Ocean acidification on marine micro organism is discussed here. It could be noted that many microscopic organisms are also vulnerable to ocean acidification. Some plankton make hard shells from calcium carbonate (limestone). These species are likely to be directly affected by ocean acidification, which will impact the rate of shell formation (calcification). Because some species will be affected more than others, ocean acidification will not only change the activity of individual phytoplankton types, but will also tend to favour some types over others. Resulting shifts in the make-up of plankton communities will affect the animals that depend on them for food. It will also influence the cycling of nutrients (such as carbon) through open ocean ecosystems. Bacteria and other types of plankton might also be affected by ocean acidification. Scientists are just beginning to understand these impacts, but it is likely that changes could affect the structure and functioning of the entire marine ecosystem.

Climate change impacts on marine plants:

The impact of climate change affects the marine plants in several ways. Many researchers such as [14,15], and [16] have indicated the impact of climate change on marine plants and implications of such studies are quite relevant from the point of view of present discussion.

The rising Sea temperature consequent upon climate change can affect the marine plants. It could be observed that rising sea temperatures will increase the production of some species of macroalgae. Changes in temperatures could also lead to changes in these species' life cycles and although there is limited available evidence on this topic, the consequences of these changes could impact food webs.

The process of ocean acidification consequent upon climate change affects the marine plants. It could be observed that nutrient concentrations in the Reef ecosystem increase due to coastal run-off, the increase in available carbon in the ocean will mean macroalgae can photosynthesis and grow at a faster rate. Larger populations of macroalgae and improved conditions for their growth will have detrimental impacts on coral reefs.

The incidence of sea level rise in the context of climate change has effect on marine plants. It is observed that sea level rise may create more available habitat space for macroalgae to grow as more land area will be inundated with water. While the increase could impact some species that live in shallow habitats by reducing their exposure to sunlight and it means more water will mean more distance for sunlight to travel to reach the macroalgae, as a group macroalgae is not vulnerable to negative impacts of sea level rise. The predicted increase in the frequency of severe weather events such as cyclones, storms and floods will bring an influx of nutrients into the Reef ecosystem, which will increase macroalgae growth and reproduction. Cyclones and storms can also destroy coral reef structures, increasing habitat areas for macroalgae to grow.

It could be noted that an important food source for dugong and marine turtles, sea grass is highly vulnerable to the impacts of climate change, particularly the species that grow in shallow and inshore habitats. The changes in Sea temperature have affect the marine plants. It is noted that sea grass photosynthesis rates are determined in part by water temperature. Increases in temperature can decrease the efficiency of photosynthesis; however the extent of this impact may be dependent on the species' reliance on light. For example, a species of sea grass that requires less light to grow will be less vulnerable to increased water temperature. The reverse is also true. Temperature also plays a role in sea grass flowering and thus reproductive patterns. Available information for this topic is limited; though it is expected temperature changes will have significant effects on the reproduction of most seagrass species.

The incidence of sea level rise in the context of climate change affects the sea grass habitat. It is observed that as the sea level rises, the depth of sea grass habitat will increase, reducing the amount of light reaching the plants. This impact could be compounded by the water quality of this habitat, as murky water also impedes the exposure of sea grass to sunlight. The inundation of water onto coastal habitats will erode the land and destroy the substrate sea grass grows from. Scientists believe it is unlikely species will migrate away from the coast.

Further climate change impact in the form of Storms and rainfall affects the marine plants storms, including cyclones, and huge rainfall that lead to flooding will have impacts on both the habitat of sea grass and their physiological processes. Winds from storms and cyclones can uproot sea grass plantations, cause erosion and bring loads of sediments from inland areas. Sea grass recovery from physical disturbances can take some time and this is being investigated following recent cyclones.

Climate change impacts on corals:

The climate change has affects the coral reef lifecycle in various ways. The climate change impacts on corals have been highlighted by many researchers. Among them $[17,18,19,20,21,22]$ are quite relevant from the point of view of present discussion.

The rising Sea temperature affects the life cycle of coral reefs. It could be noted that thermal stress is most visible when corals bleach. Too much heat means corals and zooxanthellae separate, the zooxanthellae taking the colour hence 'bleaching' and energy sources with them. Coral bleaching is not always fatal, but has been one of the main causes of coral death around the world in the last 20 years. Increased sea temperatures can also affect the growth and reproduction of corals. Experiments have shown a quicker embryo development, reduced egg and sperm production and an incomplete fertilization cycle in corals due to warm water.

The process of ocean acidification consequent upon climate change can affect the coral life span. It is observed that ocean acidification is an additional threat to coral reef survival. It reduces the corals' ability to build their skeletons. This will result in weaker coral structures, thus reducing their ability to withstand physical disturbances from storms, they will have less energy to respond to stress and disease and there will be fewer protective habitats for other marine life.

The incidence of sea level rise can affect the coral life. In this connection many studies conclude that the rate of sea level rise is slower than current coral growth and therefore may have limited impact on coral reefs. However, the accumulation of other climate change impacts may slow coral growth, exposing them to the effects of rising sea levels.

The occurrence of Storms and rainfall consequent up on climate change affects the life of coral reefs. It could be noted that storms, rainfall and floods are all natural, regularly occurring events on the coastal areas and as such, play a role in the ecosystem. However, predictions suggest an increase in the frequency of severe weather events which could lead to more serious physical damage, with less time between events to recover.

The most immediate impact is coral breakage, dislocation and degradation from wind and waves. However, the effect doesn't stop there. Heavy rainfall events lead to flood plumes stretching across the Reef, exposing inshore coral reefs to freshwater inundations. Freshwater run-off reduces salinity levels, sometimes causing bleaching, and brings increased nutrients and sediments, which can lead to disease outbreaks, algae blooms and murky water reducing light reaching corals.

The vulnerability of coral reefs to these impacts is dependent on the effect of other climate change impacts. It could be noted that reefs that are weakened by ocean acidification or stressed from high sea surface temperatures will respond poorly to a major storm or flood event. 
Climate change impacts on fish:

The climate change has various levels of effects on fish population and also phenology of fish population. It has been proved by many researchers. Among them $[23,24,25,26,27,28,29,30,31]$ are quite relevant from the point of view of present discussion.

The rising Sea surface temperature can affects the life cycle of marine fish population. It is observed that fish body temperature is moderated by water temperature. Increasing sea temperatures can affect important biological processes of fish including growth, reproduction, swimming ability and behaviour. Reproduction is only possible in a narrow temperature range, and therefore could be affected by the forecast temperature rises associated with climate change. Temperature also influences the sex of fish, which may have an effect on population dynamics. Some fish respond well to high sea temperatures, as these temperatures can shorten incubation time, increase growth rates and improve swimming ability in juvenile fish. Slight increases in temperature may be beneficial to some fish species as this can shorten incubation time, increase growth rates and improve swimming ability in juveniles. However these benefits are limited to relatively minor temperature increase.

The incidence of ocean acidification consequent of climate change has effects on fish population. Ocean acidification which is a change in ocean chemistry is also likely to impact fish reproductive processes. Fish eggs are more sensitive to $\mathrm{pH}$ changes than fish adults, and thus the population numbers may dwindle if this impact is significant. Ocean Acidification has also been shown to reduce the ability of fish larvae to find suitable habitat and find their way home. Lots of species of fish live in and around coral reefs, and most feed on the microbes in the water, which provide fish with their carbon requirements. In general, the overarching affects of ocean acidification on coral formation and the abundance of carbon in the food chain will impact fish species through habitat and food availability.

The incidence of Sea level rise in the contest of climate change can affect the fish population. The projections for sea level rise in coastal areas suggest much of the coast line will be inundated with water, resulting in major changes to mangrove and sea grass beds in these areas. These habitats provide protection and food resources for juvenile fish.

Climate change impacts on marine mammals:

Marine mammals are most vulnerable to the impacts of climate change that alter their habitats and food sources. Many researchers pointed out the impact of climate change on marine mammals. Among them $[32,33,34,35]$ are quite relevant from the point of view of present discussion.

Ocean acidification is expected to significantly alter marine ecosystems around the world, so the migratory patterns of whales may change as food becomes harder to find in their regular feeding habitats. Due to their migratory nature and thus exposure to a range of sea temperatures, it is unlikely a rise in the sea temperature will impact whales.

The rise in sea temperature may only affect dolphins by increasing their spatial range. For example, as water temperature rises across the Reef, dolphins will find more areas to their liking. Cyclones, storms and heavy rainfall will affect dolphins in coastal areas by bringing large amounts of nutrients and sediments into the inshore regions. High concentrations of heavy metals and organic compounds have damaging effects on marine mammals.

Sea temperatures are likely to increase dugong spatial range. While there is the possibility of dugong stranding after a major cyclone or storm, this is not the main risk posed by extreme weather events. Floods, cyclones and heavy rainfall often destroy sea grass beds, meaning less food is available to dugong. This scenario is likely to occur more often, and across larger areas, as climate change increases the frequency of severe weather events. The other threats to sea grass populations are rising sea level and ocean acidification. The impacts of these on sea grass will have flow-on effects for dugong populations and could result in population migration or starvation.

Climate change impacts on marine reptiles:

The climate change has impacts on marine reptiles. Such impacts have been studied by many researchers. Among them $[36,37,38,39,40,41,42,43,44]$ and are quite relevant from the point of view of present discussion.

The turtles, sea snakes and crocodiles are affected by climate change because their body temperatures are controlled by the environmental temperature. Thus many of their biological processes are affected by temperature and, increasing their vulnerability to climate change impacts. Of all the marine reptiles in the sea, turtles are the most vulnerable to climate change. It is predicted increased temperatures will significantly affect their reproductive processes and food resources.

Temperature plays a critical role in marine turtle reproduction. The beginning of a turtle's breeding cycle depends to some extent on the air temperature. Once the eggs have been laid, their development into a hatchling requires a temperature range between 25 and 33 degrees Celsius. The sex of turtles is also determined by the temperature of the sand where the eggs have been laid. Therefore, any increases to air and sea temperatures will alter turtle breeding seasons and patterns, egg hatching success and the sex ratio of the populations.

An increase in cyclone severity could impact turtle nests, as they are usually made during cyclone season. However, these impacts are likely to be localized to only a few nesting areas with each cyclone. The extent of the impact will depend on the timing of the cyclone. More rainfall may lead to more nesting success for turtles as it is difficult for a female turtle to build a nest in loose, dry sand. Evidence shows a marked improvement in nest building success following major rain events. Sea grass is a food source for some marine turtles and as the effects of climate change may reduce the amount and spread of sea grass, and its availability to turtles may decrease.

Sea snakes' body temperature is completely reliant on the sea temperature due their small body mass and surface area. However, little is known about tolerance levels and where sea snakes live and move based on their preferred sea temperature.

The estuarine crocodile nesting season coincides with cyclone season on the sea. Therefore, cyclones can sometimes result in localized flooding of crocodile nests. This could mean eggs are washed away, restricted access to nesting sites for crocodiles and a loss of available nesting area.

Climate change impacts on seabed dwellers:

The impact of climate change on seabed dwellers has been emphasized by many researchers. Among them [45,46,47,48] are quite relevant from the point of view of present discussion.

The diversity of seabed-dwelling animals means that this group includes animals with low, moderate, and high vulnerability to climate change. Benthic invertebrates (animals that live on the seabed) share a high sensitivity to increasing sea temperature. Particular types also have a moderate sensitivity to changes in ocean circulation, storm and flood events and ocean chemistry.

The effects of rising sea temperatures will vary a great deal among invertebrate species. Animals known to be sensitive to warm temperatures include sponges, sea squirts, molluscs and polychaeta worms. Water temperatures affect key aspects of animal physiology, including metabolic rate and timing of reproduction. Changes to basic functioning of animals due to temperature will affect the survival and reproductive success of certain species, with unpredictable ecological consequences. Predicted increases in extremes of water temperature are also likely to affect the survival of adults and larvae of several species. Highly mobile species such as squids and crabs are likely to be able to escape higher-than-normal temperatures. Immobile creatures, such as sponges and giant clams will be more at risk.

Any changes to ocean currents will have profound effects on the benthic invertebrates of the ocean. One key reason for this is that many seabed dwellers begin their lives floating as plankton in the open ocean, before they settle into a final home. Changes to the currents that move these planktonic larvae around the Reef would affect their dispersal to new homes, as well as their access to food in the ocean. For example, larvae could be dispersed to unsuitable habitats for settlement, reducing their rate of survival. Predicted changes in ocean acidity $(\mathrm{pH})$ will reduce the ability of these creatures to build their shells and skeletons. These sorts of changes will shift the ecological balance in the coastal area, with unpredictable but potentially profound consequences. The reduced production of limestone skeletons from benthic invertebrates (such as foraminifera's) will also reduce the supply of new sediments to coral cays and other reef features as the sea level rises. 
Citation: S. Naveen Nivas and Dr. I. Sundar, 2018. Climate Change Impact and Mitigation In Marine Biodiversity Conservation. Advances in Natural and Applied Sciences., 12(9): 6-10. DOI: 10.22587/anas.2018.12.9.2

In order to protect the marine biodiversity from the impact of climate change, some action oriented activities are required. The climate change mitigation could be done by undertaking measures to address current impacts of climate change on the ocean include significantly cutting emissions, upscaling proper protection for marine ecosystems to retain resistance and rebuild resilience, as well as implementing sustainable practices for all industries and uses across the ocean. Marine protected areas to be constructed in major coastal areas on the basis of ecosystem based adaptation and mitigation measures. In order to protect the coastal environment, there is a need to prepare and implement Integrated Coastal Zone Management and Marine Spatial Planning with the view to meet multiple objectives, including sustainable development, biodiversity conservation as well as climate change adaptation and mitigation.

Effective implementation of adaptation strategies, including National Adaptation Plans and Programmes of Action, as well as mitigation efforts such as Reducing Emissions from Deforestation and Forest Degradation and Nationally Determined Contributions under the Paris Agreement, could be decide and such actions provide opportunities to use marine protected areas as an implementation tool for ecosystem-based adaptation and mitigation.

In order to protect the marine biodiversity climate finance mechanisms can be promoted with a view to increase support for the implementation of marine and coastal ecosystem-based adaptation and mitigation. In this context, the Green Climate Fund offers an opportunity for developing countries to receive support for mitigation and adaptation efforts, with a focus on biodiversity conservation and protected area management.

It could be noted that coastal ecosystem protection can benefit from the Poznan Strategic Program on Technology Transfer, implemented by the Global Environment Facility, and the work of the UNFCCC's Technology Mechanism. The government should have effective commitments at different levels including national, regional and international towards climate change mitigation in connection with marine biodiversity conservation. Such commitments can help boost the governance of and resources available to marine protected area programmes. This can ensure that marine protected areas are effective and sufficient in number to fulfill their potential as a key tool for climate change mitigation and adaptation.

There is a need to consider the challenge to revise the global marine protected area strategy and emphasize the strong linkages between climate, sustainability and biodiversity efforts, through existing international regimes such as the UNFCCC and CBD. A new agenda for building a truly representative, consistent and resilient marine protected area network to face both climate change and the loss of biodiversity would be highly beneficial.

\section{Conclusion:}

It could be seen clearly from the above discussion that climate change has potential impact on marine biodiversity. The climate change impacts in the form of ocean acidification, rising sea temperatures, changes in ocean currents, sea level rise, changes in Sea temperature, and erratic storms and rainfall can affect the marine microscopic organisms, marine plants, corals reefs, marine fish, marine mammals, marine reptiles and seabed dwellers. The impact of climate change can be observed in phenology and breeding behavior of animals. Some species may survive and some species may not survive in the context of climate change. The protection of marine biodiversity is very essential in the context of climate change. In order to protect the marine biodiversity in the context of climate change in the following measures can be considered

1. Undertake marine ecosystem restoration projects by the ways of seeding, transplanting, or assisting colonization of coastal and marine plants, eliminating invasive species, demolishing unnecessary or unused structures, etc. where appropriate

2. Establish "Predictive Protected Areas," which provide some level of protection for areas expected to provide future refugia and areas that have demonstrated some resilience to the effects of climate change.

3. Encourage connectivity synergies between coastal and marine ecosystems by protecting ecological corridors

4. Obtain information regarding the relative magnitude of social and environmental impacts and costs of climate change and ocean acidification.

5. Increase ecosystem resilience and ensure continued provision of ecosystem services by reducing other human stressors on the marine environment, including: pollution, destructive fishing practices, habitat destruction and unsustainable coastal development.

6. Protect natural buffers and plan for inward migration of coastal ecosystems such as mangroves and wetlands.

\section{REFERENCES}

[1] Goulletquer, P., P. Gros, P. Boeuf, J. Et Weber, 2013. Biodiversiten environment marine. QUAE Editions.

[2] Poloczanska, E.S., O. Hoegh-Guldberg, W. Cheung, H.O. Pörtner and M. Burrows, 2014. Cross-Chapter Box On Observed Global Responses Of Marine Biogeogra- Phy, Abundance, And Phenology To Climate Change. In Climate Change 2014: Impacts, Adaptation, and Vulnerability. Part A: Global and Sectoral Aspects. Contribution of Working Group II to the Fifth Assessment Report of the Intergovernmental Panel on Climate Change, Cambridge University Press.

[3] Beaugrand, G.P., C. Reid, F. Ibanez, J.A. Lindley and M. Edwards, 2002, Reorganization of North Atlantic Marine Copepod Biodiversity and Climate. Science, 296: 1692-1694.

[4] Pinksy, M.L., B. Worm, M.J. Fogarty, J.L. Sarmiento and S.A. Levin, 2013. Marine Taxa Track Local Climate Velocities. Science, 341: $1239-1242$.

[5] Pörtner Ho, R., Knust, 2007. Climate change affects marine fishes through the oxygen limitation of thermal tolerance. Science, 315: 95-97.

[6] Sumaila Ur, W.W., V.W. Cheung, D. Lam, Pauly, S. Herrick, 2011. Climate change impacts on the biophysics and economics of world fisheries. Nat Clim Change, 1: 449-456.

[7] Daufresne, M., K. Lengfellner, U. Sommer, 2009. Global warming benefits the small in aquatic ecosystems. Proc Natl Acad Sci., 106: $12788-12793$.

[8] Sheridan Ja, D., Bickford, 2011. Shrinking body size as an ecological response to climate change. Nat Clim Change, 1: 401-406.

[9] Cheung, W.W., J.l Sarmiento J., Dunne, T.1. Frölicher, V.W. Lam, M.D. Palomares, R. Watson, D. Pauly, 2013. Shrinking of fishes exacerbates impacts of global ocean changes on marine ecosystems. Nat Clim Change, 3: 254-258.

[10] Ben Rais Lasram, F., J.A. Tomasini, F. Guilhaumon, M.S. Romdhane, T. Do Chi, D. Mouillot, 2008. Ecological correlates of dispersal success of Lessepsian fishes. Marine Ecology Progress Series, 363: 273-286.

[11] Mackas, D.L., S. Batten, M. Trudel, 2007. Effects on zooplankton of a warmer ocean: recent evidence from the North Pacific, Progress in Oceanography, 75: 223-52.

[12] Ries, J.B., A.L. Cohen, D.C. McCorkle, 2009. Marine calcifiers exhibit mixed responses to CO2-induced ocean acidification, Geology, 37: $1131-1134$.

[13] Santos, H.F., F.L. Carmo, G. Duarte, F. Dini-Andreote, C.B. Castro, A.S. Rosado, 2014. Climate change affects key nitrogen-fixing bacterial populations on coral reefs. The ISME Journal.

[14] Fields, P.A., Graham, J.B., R.H. Rosenblatt, G.N. Somero, 1993. Effects of expected global climate change on marine faunas. Trends Ecol. Evol., 8: 361367.

[15] Morán, X.A.G., Á. López-Urrutia, A. Calvo-Díaz, W.K.W. Li, 2010. Increasing importance of small phytoplankton in a warmer ocean, Global Change Biology, 16-1137.

[16] Po"rtner, H.O., M. Langenbuch, 2005. Synergistic effects of temperature extremes, hypoxia, and increases in CO2 on marine animals: From Earth history to global change.

[17] Knowlton, N., 2001. The future of coral reefs. Proceedings of the National Academy of Sciences, USA, 98: 5419-5425

[18] Hughes, T.P., A.H. Baird, D.R. Bellwood, M. Card, S.R. Connolly, C. Folke, 2003. Climate change, human impacts, and the resilience of coral reefs. Science, 301: 929-933.

[19] Precht, W.F., R.B. Aronson, 2004. Climate flickers and range shifts of reef corals. Front. Ecol. Environ., 2: 307-314.

[20] Ferrari, M.C.O., D.L. Dixson, P.L. Munday, M.I. McCormick, M.G. Meekan, A. Sih, and D.P. Chivers, 2011. Intrageneric variation in antipredator responses of coral reef fishes affected by ocean acidification: Implications for climate change projections on marine communities. Global Change Biology 17(9): 29802986.

[21] Sinutok, S., R. Hill, M.A. Doblin, M. Kühl, P.J. Ralph, 2012. Microenvironmental changes support evidence of photosynthesis and calcification inhibition in Halimeda under ocean acidification and warming. Coral Reefs, 31: 1201-1213. 
[22] Kroeker, K.J., R.L. Kordas, R. Crim, I.E. Hendriks, L. Ramajo, G.S. Singh, C.M. Duarte, and J-P. Gattuso, 2013. Impacts of ocean acidification on marine organisms: Quantifying sensitivities and interaction with warming. Global Change Biology, 19(6): 1884-1896

[23] Southward, A.J., G.T. Boalch, L. Maddock, 1988. Fluctuations in the herring and pilchard fisheries of Devon and Cornwall linked to change in climate since the 16th century, Journal of the Marine Biological Association of the UK, 68: 423-445.

[24] Edwards, M., A.J. Richardson, 2004. Impact of climate change on marine pelagic phenology and trophic mismatch. Nature, 430: 8811-8884

[25] Perry, A.L., P.J. Low, J.R. Ellis, J.D. Reynolds, 2005. Climate change and distribution shifts in marine fishes. Science, 308(5730): 1912-1915. 1

[26] Ottersen, G., D. Hjermann, N.C. Stenseth, 2006. Changes in spawning stock structure strengthens the link between climate and recruitment in a heavily fished cod stock, Fisheries Oceanography, 15: 230-243.

[27] Fogarty, M., L. Incze, K. Hayhoe, D. Mountain, J. Manning, 2008. Potential climate impacts on Atlantic cod (Gadus morhua) off the northeastern USA, Mitgation Adaptation Strategies for Global Change, 13: 453-466.

[28] Sundby, S., O. Nakken, 2008. Spatial shifts in spawning habitats of Arcto-Norwegian cod related to multidecdal climate oscillations and climate change, ICES Journal Marine Science, 65: 953-962.

[29] Gibson, G.A., Y.H. Spitz, 2011. Impacts of biological parameterization, initial conditions, and environmental forcing on parameter sensitivity and uncertainty in a marine ecosystem model for the Bering Sea, Journal of Marine Systems, 88: 214-231.

[30] Hollowed, A.B., M. Barange, S. Ito, S. Kim, H. Loeng, Effects of climate change on fish and fisheries: forecasting impacts, assessing ecosystem responses, and evaluating management strategies Preface, ICES Journal of Marine Science, 68: 984-985.

[31] Petitgas, P., A.D. Rijnsdorp, M. Dickey-Collas, G.H. Engelhard, M.A. Peck, J.K. Pinnegar, K. Drinkwater, 2013. Impacts of climate change on the complex life cycles of fish, Fisheries Oceanography, 22: 121-139.

[32] Fields, P.A., J.B. Graham, R.H. Rosenblatt, G.N. Somero, 1993. Effects of expected global climate change on marine faunas. Trends Ecol. Evol., 8: $361-367$.

[33] Po"rtner, H.O., M. Langenbuch, 2005. Synergistic effects of temperature extremes, hypoxia, and increases in $\mathrm{CO} 2$ on marine animals: From Earth history to global change.

[34] Harley, C.D.G., A.R. Hughes, K.M. Hultgren, B.G. Miner, C.J.B. Sorte, C.S. Thornber, 2006. The impacts of climate change in coastal marine systems. Ecology Letters, 9: 228-241.

[35] Howard, J., E. Babij, R. Griffis, B. Helmuth, A. Himes-Cornell, P. Niemier, M. Orbach, 2013. Oceans and marine resources in a changing climate. Oceanography and Marine Biology: An Annual Review, 51: 71-192.

[36] GlobHays, G.C., A.C. Broderick, F. Glen and B.J. Godley, 2003. Climate change and sea turtles: a 150-year reconstruction of incubation temperatures at a major marine turtle rookery. Global Change Biology, 9: 642-646.

[37] Guinea, M.L., S.D. Whiting, 2005. Insights into the distribution and abundance of sea snakes at Ashmore Reef. The Beagle, Supplement, 1: 199-205.

[38] McMahon, C.R., G.C. Hays, 2006. Thermal niche, large-scale movements and implications of climate change for a critically endangered marine vertebrate.

[39] Hawkes, L.A., A.C. Broderick, M.H. Godfrey, B.J. Godley, 2007. Investigating the potential impacts of climate change on a marine turtle population. Global Change Biology, 13: 923-32.

[40] Poloczanska, E.S., C.J. Limpus, G.C. Hays, 2009. Vulnerability of marine turtles to climate change. In 'Advances in marine biology'. (Ed. D.W. Sims), 151211.

[41] Hays, G.C., S. Fossette, K.A. Katselidis, G. Schofield, M.B. Gravenor, 2010. Breeding periodicity for male sea turtles, operational sex ratios, and implications in the face of climate change. Conservation Biology 24: 1636-1643.

[42] Fuentes, M., D. Abbs, 2010. Effects of projected changes in tropical cyclone frequency on sea turtles. Marine Ecology Progress Series, 412: 283-292.

[43] Fuentes, M.M.P.B., B.L. Bateman and M. Hamann, 2011b. Relationship between tropical cyclones and the distribution of sea turtle nesting grounds. Journal of Biogeography, 38: 1886-1896.

[44] Hamann, M., M.M.P.B. Fuentes, N.C. Ban, V.J.L. Mocellin, 2013. Climate change and marine turtles, 353-397. in Wyneken, J., Lohmann, K.J., Musick, J.A. (eds.) . The Biology of Sea Turtles Volume III, CRC Press, Boca Raton, FL.

[45] Fields, P.A., J.B. Graham, R.H. Rosenblatt, G.N. Somero, 1993. Effects of expected global climate change on marine faunas. Trends Ecol. Evol., 8: 361-367.

[46] Po"rtner, H.O., M. Langenbuch, 2005. Synergistic effects of temperature extremes, hypoxia, and increases in CO2 on marine animals: From Earth history to global change.

[47] Harley, C.DG., A.R. Hughes, K.M. Hultgren, B.G. Miner, C.J.B. Sorte, C.S. Thornber, 2006. The impacts of climate change in coastal marine systems. Ecology Letters, 9: 228-241.

[48] Howard, J., E. Babij, R. Griffis, B. Helmuth, A. Himes-Cornell, P. Niemier, M. Orbach, 2013. Oceans and marine resources in a changing climate. Oceanography and Marine Biology: An Annual Review, 51: 71-192. 